\title{
Finite-Element Limit Analysis of the Tucker High School Gymnasium Roof Failure
}

\author{
Peter T. Laursen
}

and Edmond P. Saliklis

\begin{abstract}
The Randolph Tucker High School gymnasium roof failure of 1970 has received much scholarly attention. This study will provide a conclusion to a large body of previously published works by means of limit state analysis of the roof failure using state of the art parametric finite-element modeling. Parametric modeling within a general purpose finite-element analysis program allows for extremely rapid changes to the model because key terms are objects or parameters that can be adjusted internally by the program, rather than laboriously entered by the user. The failure of the roof was investigated by means of a limit state analysis, which accurately captured the cracking of the concrete and the yielding of the reinforcing steel. Concrete creep and shrinkage and relaxation of the prestressing steel were also accounted for. Finally, the authors also studied the idea that camber in the roof geometry might have prevented collapse.
\end{abstract}

Author keywords: Finite-element method; Limit analysis; Failure modes; Hyperbolic parabolic shells.

\section{Introduction}

The purpose of this paper is threefold. One of its purposes is to introduce the capabilities of a new state-of-the-art parametric finite-element tool which can perform accurate limit state analyses of concrete structures. The other is to use this tool to perform a limit state study of the failure of a shallow gabled hyperbolic paraboloid (hypar) roof that has garnered much scholarly attention. The final purpose is to explore the idea that slightly altering the geometry of the structure, specifically the ridge beam camber, may have prevented its collapse.

The tool we present is a sophisticated finite-element model that accurately accounts for the myriad of components making up a reinforced concrete structure, including the type of aggregate used, the amount of prestressing, the relaxation of the prestressing, and the shrinkage and creep of the concrete. Furthermore, this tool can explore large deformations, and it can perform true limit state analyses wherein the internal forces are redistributed as needed to achieve equilibrium as more and more of the concrete cracks or crushes and steel begins to yield.

The case study researched was the collapse of the Tucker High School gymnasium roof in 1970. This failure was examined to demonstrate convincingly the engineering mechanisms that caused this collapse and to propose a convincing conclusion to a number of scholarly papers devoted to this case.

Another compelling reason to study this roof collapse ties into the final purpose of this paper, namely to explore an idea proposed by a prominent thin shell designer about this structure. Milo Ketchum Jr. suggested in his memoirs (Ketchum 1990), written shortly before his death, that the collapse of this structure may have been prevented if the roof ridge beams had been cambered, thus obtaining a potentially stronger load carrying member in both bending and arching action. The camber of the roof ridge beams became a parameter that could be explored through the parametric finite-element modeling tool, and Ketchum's suggestion was extensively explored.

\section{Background}

The Randolph Tucker High School gymnasium was completed in 1963 in Henrico County, Virginia. The roof concrete was placed in November of 1962. In 1970, it collapsed after significant sagging of the roof was noticed. Fortunately, the students in the gym escaped without injury ("Students" 1970). The investigative forensic team recorded enormous deformations in companion shells built at the same time as Tucker ("Design" 1970), deformations on the order of $0.45 \mathrm{~m}$ (18 in) (Ketchum 1990). This was not the only shallow gabled hypar collapse of the 1970s, a similar design collapsed at the Cheyenne Municipal Airport in 1975 ("15-year-old HP" 1970).

Investigations of the cause of the Tucker roof failure have to this date produced suggestive evidence. Edwards and Billington (1998) summarized previous investigations and postulated that failure was because of the design error of not taking secondary moments and time effects, such as concrete creep and shrinkage into account. They concluded that creep and shrinkage contribute greatly to the roof deflection and therefore affected the roof strength. A large-scale NSF funded study concurred with this assessment (Gallegros-Cazares and Schnobrich 1988), but it also suggested that camber in the design of such shallow gabled hypars may have been beneficial. Lateral movement of the supporting columns of shallow hypars has also been implicated in such failures (Simmonds 1989).

Milo Ketchum Jr., a prominent engineer and early advocate of thin-shelled concrete hypar roofs in the United States, pondered 
the failure of the Tucker High School roof. "It was a good 10 years", he stated in his memoir (Ketchum 1990), "before it finally occurred to me what the real design fault was. It shows that when you design shells, all your normal instincts flee. The center point should have been cambered upward". Ketchum was familiar with the Tucker High School roof collapse because he was a consultant to one of the investigating teams. This paper will conclude with an investigation of Ketchum's camber hypothesis.

The Tucker Gym hypar roof was designed according to the thin membrane theory that was widely accepted at the time. Later investigations have shown the membrane theory to be inappropriate for such structures (Billington 1990). Even a simple arch analogy for arching diagonally across the Tucker roof aligns well with results obtained by finite-element models (Edwards and Billington 1998). The lesson from the arch analogy is that the lateral thrust from the roof to be restrained by the tie beams (refer to Figs. 1 and 2) may have been twice as high as the thrust predicted from the thin membrane theory applied at the time of design.

This paper presents new and more definitive answers to the cause of failure based on state-of-the-art finite-element analysis. Use of the proprietary FEM software package "IBDAS" (Integrated Bridge Design and Analysis System) (Andersen et al. 1994), developed by the international engineering consultant COWI A/S, Denmark, allowed for sophisticated failure analysis of the roof.

Results presented herein aim to quantify 1) the effects of creep and shrinkage on the roof behavior, 2) the maximum roof load capacity using limit state analysis, and 3) the effect that camber of the ridge center point has on the roof strength.

\section{Modeling}

The basic geometry of the roof is shown schematically in Figs. 1 and 2. The width of the edge beams (AB) is $356 \mathrm{~mm}$ (14 in.) and their depth varies from 419 to $662 \mathrm{~mm}$ (16.5 to $24.5 \mathrm{in}$.) near the supports. The ridge beam ( $\left.\mathrm{CC}^{\prime}\right)$ is $1.82 \mathrm{~m}(6 \mathrm{ft})$ wide and its height varies from 330 to $597 \mathrm{~mm}$ (13 to $23.5 \mathrm{in}$.) near the center point (soffit width varies depending on beam height and roof inclination). The tie beams spanning between the corner points $\mathrm{B}$ and $\mathrm{BB}^{\prime}$ are rectangular, $356 \mathrm{~mm}$ (14 in.) wide and $406 \mathrm{~mm}$ (16 in.) deep (see also Fig. 2). The nominal thickness of the shell is $89 \mathrm{~mm}$ (3.5 in.),

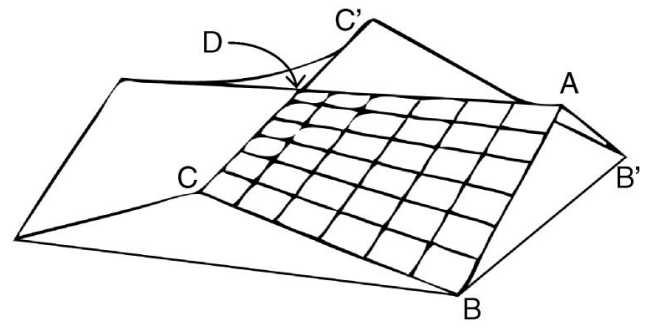

Fig. 2. Schematic of roof

and it thickens from $89 \mathrm{~mm}$ (3.5 in.) to $152 \mathrm{~mm}$ (6 in.) towards the ridge and edge beams over a distance of $1,219 \mathrm{~mm}(4 \mathrm{ft})$. The total

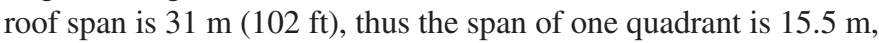
as shown in Fig. 1. The rise of the roof is $4.72 \mathrm{~m}(15.5 \mathrm{ft})$, measured from the centerline of the tie beams to the peak of the roof at points A or $\mathrm{C}$, which are at the same elevation. Lightweight concrete is used and characterized by a density of $18.1 \mathrm{kN} / \mathrm{m}^{3}$ (115 pcf), a strength of $27.8 \mathrm{MPa}(4,000 \mathrm{psi})$, and a Young's modulus of $17.2 \mathrm{GPa}(2,490 \mathrm{ksi})$. Shell reinforcement [414 MPa (60 ksi)] consists of 13-mm (\#4) bars on top at 178-mm (7-in.) spacing in the direction A-C and 13-mm (\#4) bars on the bottom at 305-mm (12-in.) spacing in the orthogonal direction B-D. Ridge beam reinforcement consists of five 29-mm (\#9) bars, top and bottom. Edge beam reinforcement consists of two 35-mm (\#11) bars, top and bottom. The prestressing in each tie beam consists of 4 Freyssinet cables type 12-0.276, each comprised of twelve 7-mm (0.276-in.) diameter wires with a rupture strength $f_{\text {pu }}=1,627 \mathrm{MPa}(236 \mathrm{ksi})$. Each cable is stressed to $289 \mathrm{kN}$ (65 kips) $\left(38.5 \% f_{\mathrm{pu}}\right)$.

The basis of the IBDAS model is the parametric geometry model shown in Fig. 3. The geometry model is logically built on a series of selected parameters, notably the shell thickness, plan dimensions of a quadrant, and the elevations of points $\mathrm{A}, \mathrm{B}$, and $\mathrm{C}$. The finite-element meshing and iterative solution schemes are continuously automatically updated and recompiled. The finiteelement model shown in Fig. 4 consists of 8-node isoparametric parabolic shell elements throughout, except for 3-node isoparametric parabolic beam elements used exclusively for the edge and tie beams. The shell in the central part of the roof is meshed with a

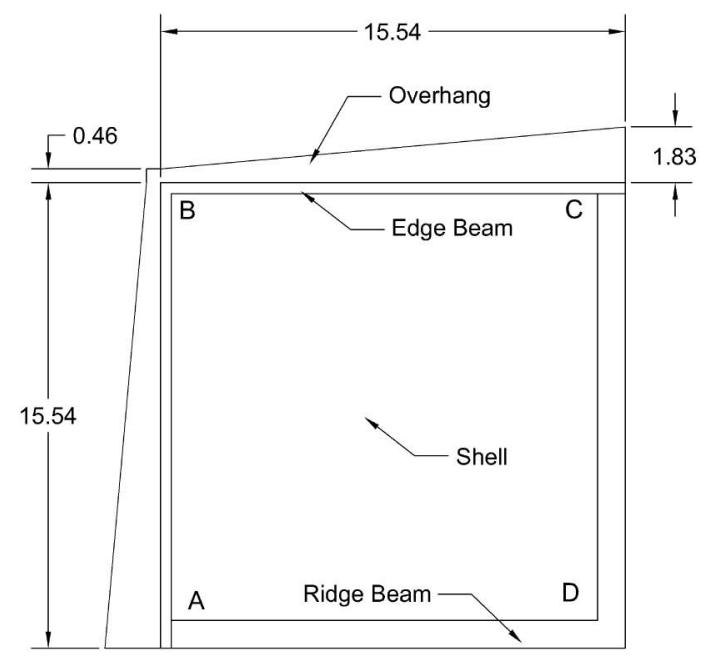

(a)
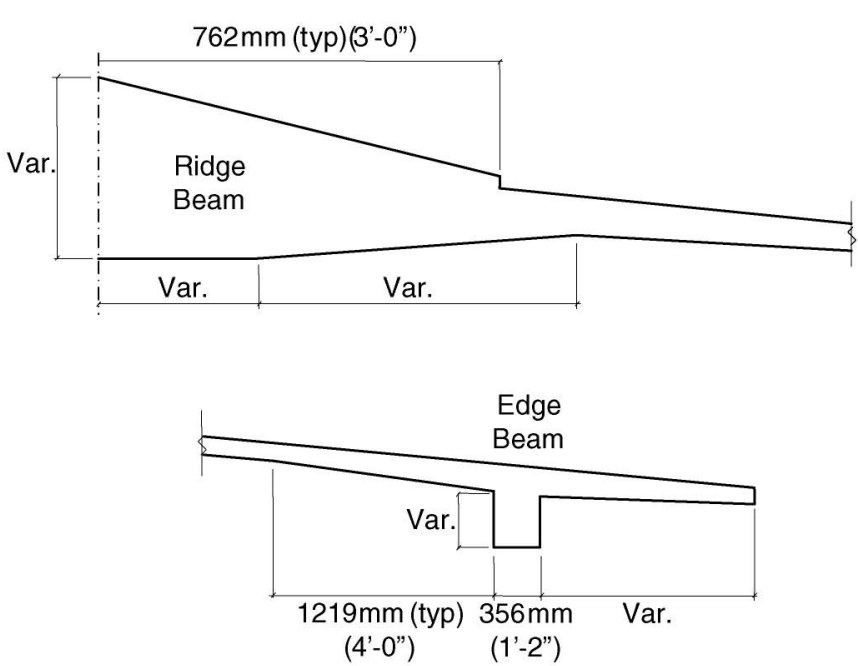

(b)

Fig. 1. Roof geometry: (a) one quadrant, plan view, dimensions in meters $(1 \mathrm{~m}=3.28 \mathrm{ft}$ ); and (b) edge and ridge beam details 

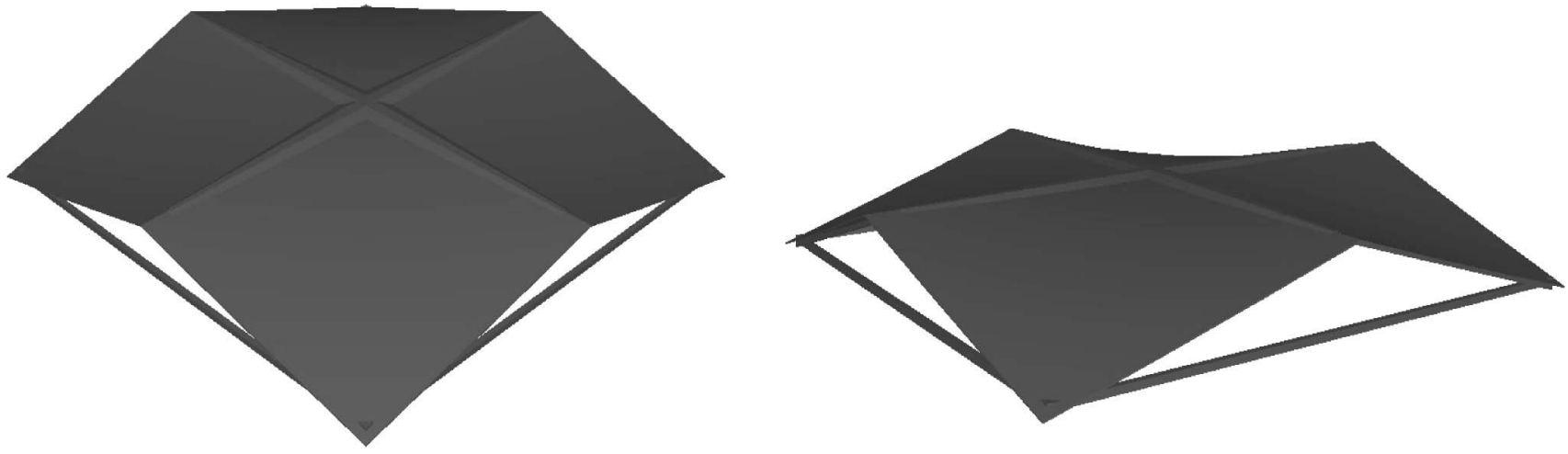

Fig. 3. IBDAS Geometry model
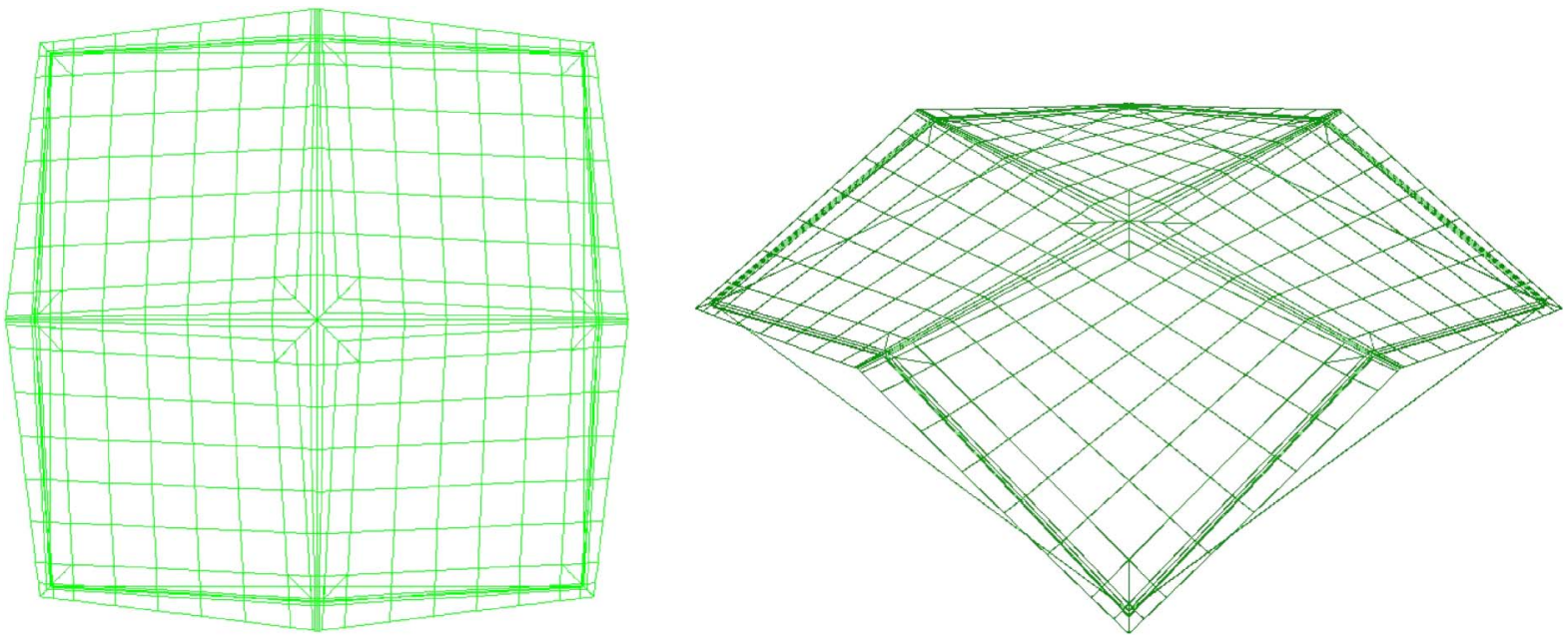

Fig. 4. IBDAS finite-element model plan, and isometric views

$5 \times 5$ grid of shell elements in each quadrant. Concrete creep and shrinkage, and prestressing steel relaxation are accounted for using the CEB-FIP Model Code 1990 (Comite Euro-International Du Beton 1993) as an integral part of the IBDAS material model. Calculations include second-order effects (large deformation formulation). Prestressing cables in the tie beams are fully accounted for, which is an improvement over previous modeling of the Tucker High School roof found in the literature. Lateral restraint of the reinforced concrete shell is provided exclusively by the prestressed tie beams. Our analysis showed that the reinforced concrete piers supporting the roof corners provided negligible lateral restraint. The total self-weight of the model excluding the tie beams is 2.77 MN (622 kips).

Perhaps the most significant model improvement over previous studies is that IBDAS allows for true strength limit state analysis. In such analyses, all elements in the model representing the concrete are assigned reinforcement (mild or prestressing as described previously) true to the reinforcing amount, and to location and direction in the cross section. In the strength limit state analyses, the actual state of each cross section (specifically at each Gauss point) is determined by using the strength limit state material descriptions and safety factors according to the American Concrete Institute (ACI) 318-08 building code (ACI 2008), all of which are parameters embedded in the IBDAS standard material model. This naturally limits the capacity of any cross section as the reinforcement yields or the concrete crushes and results in a modified (reduced) stiffness of each element depending on the level of flexural cracking, which directly modifies the global stiffness matrix of the finite-element model. Subsequent iterations will result in redistribution of internal forces as possible. In other words, as cracking develops in the reinforced concrete cross sections as a result of bending moment and axial force, the effective stiffness of the structure tends to reduce significantly, thus causing redistribution of internal forces and larger deflections. The overall structural capacity is calculated as the highest load at which convergence (equilibrium) can be achieved.

\section{Analysis Matrix}

Two series of analysis were conducted: elastic analysis (EL) which included analyses of creep and shrinkage, and second-order effects for the roof subjected to nominal self-weight (1.0 SW), and limit state analysis (LS) — which increased the applied load until failure was induced. Assessment of the effect of camber of the center point D was conducted only for the limit state analyses. Table 1 shows the matrix of all model variants, in which short term (ST) means no creep and shrinkage and long term (LT) includes creep and shrinkage. First and second refer to without (1ST) and with (2ND) second-order effects. $\mathrm{C}$ is the camber of point $\mathrm{D}$ with respect to points $\mathrm{A}$ and $\mathrm{C}[\mathrm{C} 00$ means zero, $\mathrm{C} 12$ means $305 \mathrm{~mm}$ (12 in.), and C18 means $457 \mathrm{~mm}$ (18 in.)].

The IBDAS creep and shrinkage calculations were based on a time span of 100 years and a concrete age of 30 days at load 
Table 1. Finite-Element Models

\begin{tabular}{|c|c|c|c|c|c|c|}
\hline Series & Model & Analysis type & Time span & Calculation order & Self-weight multiplier & Camber \\
\hline \multirow[t]{4}{*}{1} & EL-ST-1ST & EL & ST & $1 \mathrm{ST}$ & 1.00 & - \\
\hline & EL-ST-2ND & EL & ST & $2 \mathrm{ND}$ & 1.00 & - \\
\hline & EL-LT-1ST & EL & LT & $1 \mathrm{ST}$ & 1.00 & - \\
\hline & EL-LT-2ND & EL & LT & $2 \mathrm{ND}$ & 1.00 & - \\
\hline \multirow[t]{4}{*}{2} & LS-1.00SW-C00 & $\mathrm{LS}$ & LT & $2 \mathrm{ND}$ & 1.00 & $\mathrm{C} 00$ \\
\hline & LS-1.34SW-C00 & $\mathrm{LS}$ & LT & $2 \mathrm{ND}$ & 1.34 & $\mathrm{COO}$ \\
\hline & LS-1.80SW-C12 & LS & LT & $2 \mathrm{ND}$ & 1.80 & $\mathrm{C} 12$ \\
\hline & LS-2.22SW-C18 & LS & LT & $2 \mathrm{ND}$ & 2.22 & C18 \\
\hline
\end{tabular}

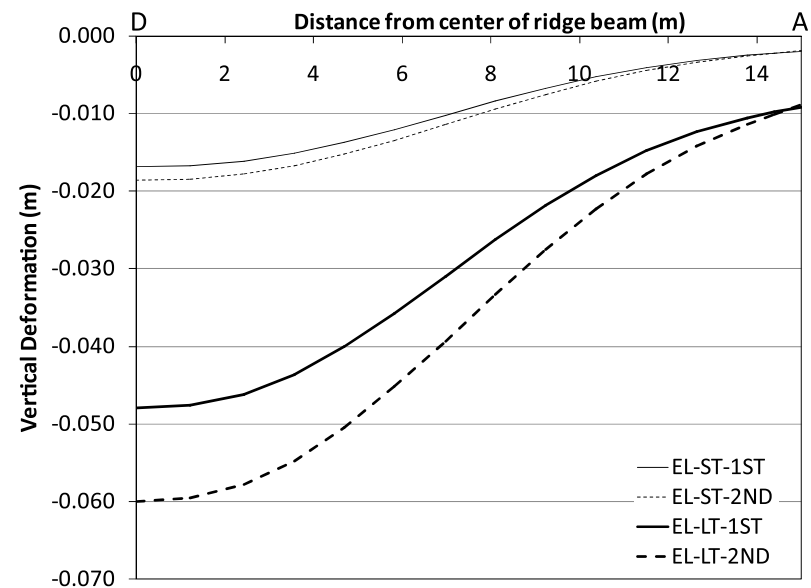

(a)

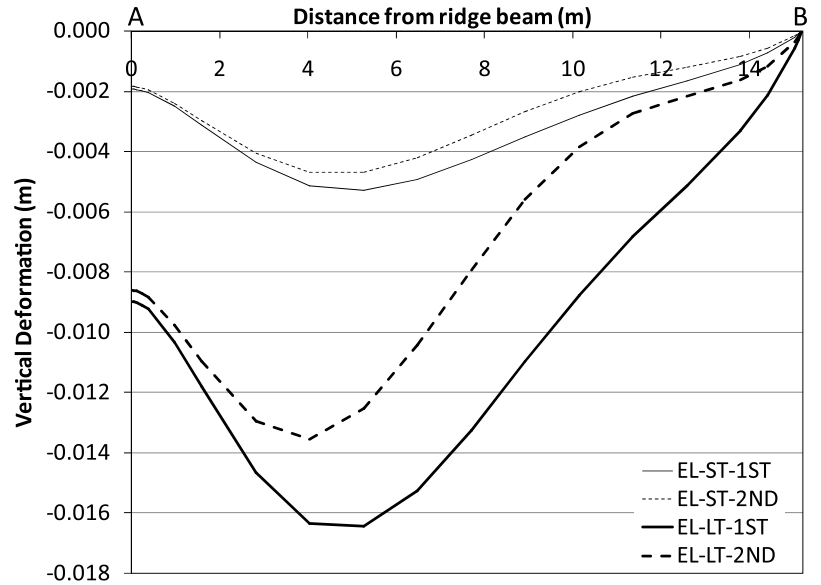

(b)

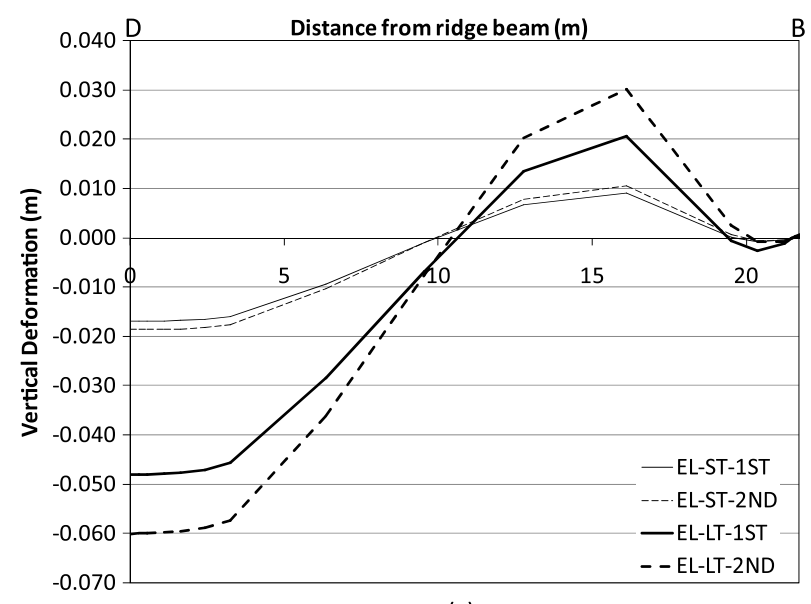

(c)

Fig. 5. Vertical deformation, elastic analyses: (a) ridge beam (DA); (b) edge beam (AB); and (c) shell along diagonal (DB)

transfer. The expected creep and shrinkage at the time of collapse about 8 years after construction were assessed to be 92 and $99 \%$, respectively, of the 100 year values, thus the authors concluded that the 100-year value was acceptably accurate (CEB-FIP 1990).

\section{Results}

\section{Elastic Analysis}

Fig. 5 shows the vertical deformation of the ridge beam (line DA in Fig. 2), the edge beam (line AB in Fig. 2), and the diagonal line of the shell (line DB in Fig. 2), respectively for the roof subjected to nominal self-weight in four conditions: immediately after construction (ST) and after all losses (LT), without and with second-order effects accounted for (1ST/2ND).

Looking at the ridge beam deflection in Fig. 5(a) and comparing EL-ST-1ST to EL-LT-1ST, the center point deformations are $17 \mathrm{~mm}$ (0.66 in.) and $48 \mathrm{~mm}$ (1.89 in.), respectively. Creep and shrinkage contribute significantly to the shell deformation by increasing it approximately three-fold. Comparing the second-order analyses to the first-order ones (EL-ST-1ST to EL-ST-2ND for example) in Fig. 5(a), second-order effects increase the deformation of the center point approximately $25 \%$. Both creep and shrinkage have significant influence on the roof deflections; however, the 


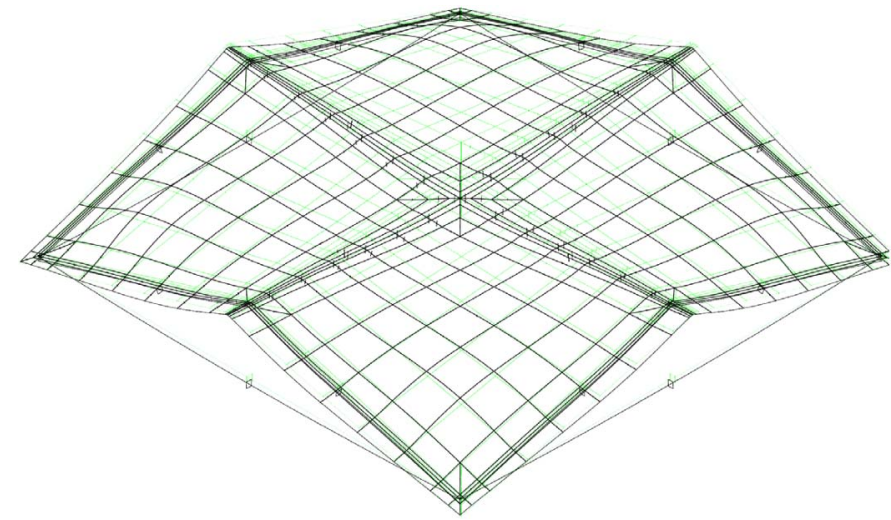

Fig. 6. Roof deformed shape, elastic analysis, model EL-LT-2ND, 20 times scale

long-term deformation of the center point of $60 \mathrm{~mm}$ (2.36 in.) under nominal self-weight does not indicate imminent failure of the structure. The edge beam deformation plotted in Fig. 5(b) shows similar behavior for EL ST versus the EL LT behavior. Fig. 5(c) illustrates the vertical displacement of the roof along the diagonal between the roof center and a corner (Line DB in Fig. 2). The results of Fig. 5(c) demonstrate that the shell tends to deflect upwards towards the corners and downwards toward the center and that contributions from creep, shrinkage, and secondorder effects increase the deformations three- to four-fold. No snap-through tendency was observed, even for loading of more than 5.0 times the self weight. Fig 6 shows a deformation plot of the shell after all losses, magnified 20 times.

Table 2 summarizes the total tie beam force (external equilibrium force) and contributions from the prestressing steel and concrete (negative indicates compression).

A significant finding is that the total tie beam force exceeds the prestressing forces after all losses because of creep, shrinkage, and relaxation, causing the concrete to decompress (i.e., zero concrete force). The total tension force in the tie beam was found to be $1.05 \mathrm{MN}$ (236 kips). The prestressing force was $1.13 \mathrm{MN}$ (254 kips) immediately after stressing and $1.05 \mathrm{MN}$ (236 kips) after all losses had occurred. The loss of prestress effectively puts the concrete of the tie beam into tension, and it is expected to eventually crack. The implication of this is that the tie beams will offer a far lower degree of axial rigidity for tying the roof corners together than expected. The tension in the tie beam of $1.06 \mathrm{MN}$ (239 kips) corresponds well with the expected thrust from the arch analogy.

\section{Limit State Analysis}

Limit state analysis was executed for the four configurations given in Table 1, Series 2, all taking into account creep and shrinkage and second-order effects. The four cases represent the original structure (no camber) subjected to $1.0 \mathrm{SW}$, the original structure with $1.34 \mathrm{SW}$, a structure with $305-\mathrm{mm}$ (12-in.) camber subjected to $1.80 \mathrm{SW}$, and finally a structure with 457-mm (18-in.) camber of the center point subjected to $2.22 \mathrm{SW}$. The SW multipliers of $1.34,1.80$, and 2.22 are not arbitrary, they are the highest loads for which the IBDAS model found convergence for a given camber and thus, represent the overall strength of the structure.

As seen in Table 2, the limit state analyses revealed that the concrete in the tie beams cracks. Effectively the tie beam rigidity is solely provided by the prestressing steel itself because the concrete is no longer in compression. This inefficiency allowed lateral expansion of the shell corners that resulted in further vertical shell deformation and associated cracking. These additive effects contributed to the reduction of the overall strength of the roof.

Fig. 7 shows the roof deformations for the four limit state analyses with the elastic long-term second-order plot superimposed as a reference plot in light gray. Fig. 7(a) shows the ridge beam deformation, and the limit state analysis for the original structure experiencing $1.0^{*}$ Self Weight increases the center point deformation to $149 \mathrm{~mm}$ from the $60 \mathrm{~mm}$ found in the elastic analysis. Clearly, the cracked concrete sections have softened the structure significantly and redistributed the internal forces. The limit state analyses indicated steel yielding and inelastic concrete deformation in the edge beams near the supports and in the ridge beam at the center and at quarter points. No inelastic deformations were observed in the 89 -mm (3.5-in.) thickness shell regions.

Pushing the original structure to near failure with $1.34 *$ Self Weight results in a center point deformation of about $417 \mathrm{~mm}$ (16.4 in.), a 2.8-fold increase in comparison to the $1.0 *$ Self Weight results. The limit state analyses indicate that steel yielding and inelastic concrete deformation has spread to most parts of the edge and ridge beams, and furthermore had spread into thin part of the shell about $6 \mathrm{~m}$ (19.7 ft) from the corner support (the area where the shell bubbles up in Fig. 8).

The roof structure is essentially barely capable of carrying its self-weight once all losses have occurred. Other sources of load could have come from additional roofing materials and items mounted to the ceiling. The center deformation of $417 \mathrm{~mm}$ (16.4 in) corresponds well with visual observation of the roof sag shortly before failure.

Significantly, we found that increasing the camber by 12 in. increases the roof strength by $34 \%$ and an 18 -in. camber increases the roof strength by $66 \%$. These models show identical failure patterns as LS-1.34SW-C00. Fig. 8 shows a deformation plot of the roof in its original configuration under $1.34 *$ Self Weight at $20 \mathrm{x}$ magnification scale.

Table 2. Tie Beam Forces

\begin{tabular}{lcccc}
\hline Series & Model & Total MN (kips) & Prest.MN (kips) & Concrete MN (kips) \\
\hline 1 & EL-ST-1ST & $1.06(239)$ & $1.13(254)$ & $1.13(254)$ \\
& EL-ST-2ND & $1.06(239)$ & $1.05(236)$ & $-0.07(-16)$ \\
& EL-LT-1ST & $1.05(236)$ & $1.05(236)$ & $0.07(-16)$ \\
2 & EL-LT-2ND & $1.05(236)$ & $1.05(236)$ & 0.00 \\
& LS-1.00SW-C00 & $1.05(236)$ & $1.40(315)$ & 0.00 \\
& LS-1.34SW-C00 & $1.40(315)$ & $1.86(419)$ & 0.00 \\
& LS-1.80SW-C12 & $1.86(419)$ & $2.30(518)$ & 0.00 \\
\hline
\end{tabular}




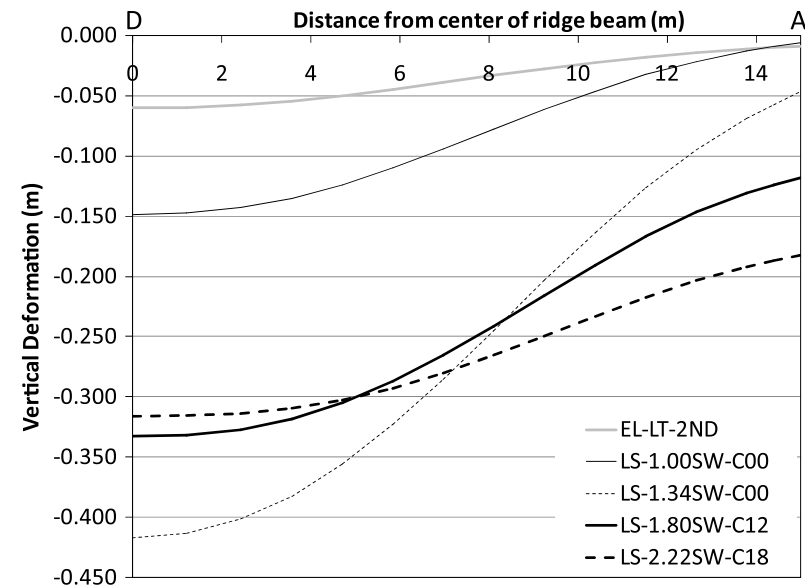

(a)

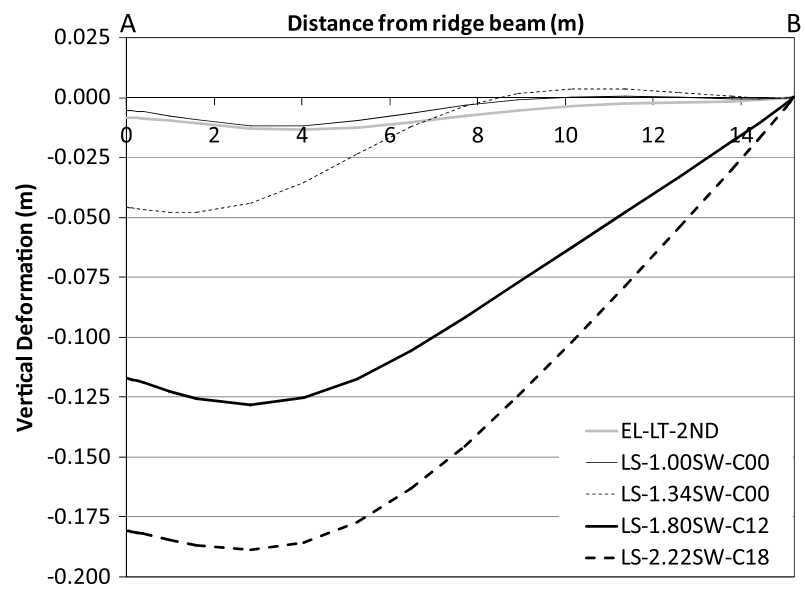

(b)

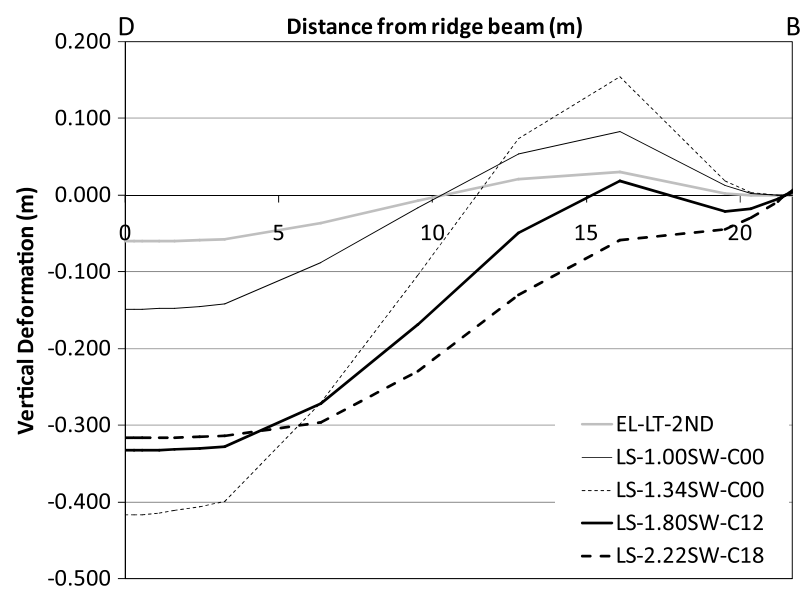

(c)

Fig. 7. Vertical deformation, limit state analyses: (a) ridge beam (DA); (b) edge beam (AB); and (c) shell along diagonal (DB)

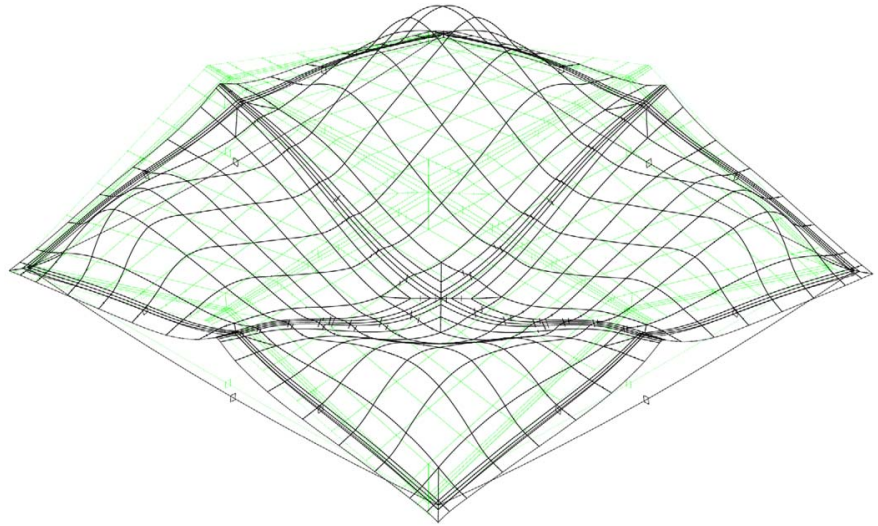

Fig. 8. Roof deformed shape, limit state analysis, model LS-1.34SWC00, 20 times scale

\section{Conclusions}

Creep and shrinkage effects clearly contribute to the roof deformation. However, concrete cracking and second-order effects appear to contribute to a far higher degree to the roof deformation. Limit state analyses show that extensive concrete cracking occurs in the roof subjected to self-weight only, causing redistribution of forces and a three- to four-fold increase of vertical deformation in comparison to purely elastic modeling. In the $1.0^{*}$ Self Weight condition, steel yielding and inelastic concrete deformation occurs in the edge beams near the supports and in the ridge beam at the center and at quarter points. The ability to track the redistribution of stresses as concrete and steel elements fail is a significant feature of the powerful limit state analysis.

Limit state analysis shows that the original structure can sustain only $1.34 \mathrm{SW}$, or $34 \%$ more weight than the nominal structural concrete weight. This suggests that the structure had little or no spare capacity for any superimposed dead load, unintended dead load, or environmental loads, such as wind and snow. The failure mode was attributed to flexural failure of the ridge beam. The tie beams are critical members for the structure and appear to be under designed, perhaps because the design forces arose from the inapplicable thin membrane theory. The concrete tie beams became ineffective once they became overburdened and what was meant to be prestressed concrete no longer experienced any compression.

Introducing a roof camber of 12 or 18 in. clearly increases the roof capacity and possibly may have prevented the catastrophic failure. Ketchum's thesis of introducing camber in the ridge beam to increase the overall strength appears warranted.

Further and perhaps more reasonable design improvements would be to prestress the edge and ridge beams and to ensure that the tie beams remain in compression at any given time for any given load combination. A parametric modeling tool can be used to detect the redistribution of forces in a concrete structure that experiences 
cracking and imminent failure. This tool was used to definitively study a well-documented roof failure and to provide new insights into the hypothesis that camber of the ridge beam would indeed have significantly increased the capacity of the roof.

\section{Acknowledgments}

The authors are grateful to COWI A/S, Denmark for providing access to IBDAS and to P.F. Jakobsen for modeling assistance.

\section{References}

American Concrete Institute (ACI). (2008). "Building code requirements for structural concrete and commentary.” ACI 318-08, Farmington Hills, MI.

Andersen, G. B., Jakobsen, P. F., and Sørensen, K. A. (1994). "Integrated design and analysis of cable supported bridges." Proc., 3rd Symp. on Strait Crossings '94, Taylor \& Francis, Oxford, UK, 258-291.

Billington, D. P. (1990). Thin shell concrete structures, McGraw-Hill,
New York, 275-283.

Comite Euro-International Du Beton. (1993). "CEB-FIP model code 1990, Thomas Telford, London". Lausanne, Switzerland

"Design errors blamed for gym collapse." (1970). Engineering News Record, 20.

Edwards, N. P., and Billington, D. P. (1998). "FE analysis of tucker high school roof using nonlinear geometry and creep." J. Struct. Eng., 124(9), 984-991.

Gallegros-Cazares, S., and Schnobrich, W. C. (1988). "Effects of creep and shrinkage on the behavior of reinforced concrete gable roof hyperbolicparaboloids." Rep. SRS 543, Dept. of Civil Engn., Univ. of Illinois, Urbana, IL.

Ketchum, M. S. (1990). "Career memories: A significant failure." Milo Ketchum archives: Manuscripts by Milo Ketchum, 〈http://www .ketchum.org/-milo/failure.html〉 (Feb. 2, 2009).

Simmonds, S. (1989). "Effect of support movement on hyperbolic paraboloid shells." J. Struct. Eng., 115(1), 19-31.

"Students clear gym moments before roof fails." (1970). Engineering News Record, 11.

“15-year-old HP roof fails, injuring 18." (1970). Engineering News Record, 12. 